\title{
Wild-type APC predicts poor prognosis in microsatellite-stable proximal colon cancer
}

Robert N Jorissen 1,2,16, Michael Christie 1,3,16, Dmitri Mouradov ${ }^{1,2}$, Anuratha Sakthianandeswaren ${ }^{1,2}$, Shan $\mathrm{Li}^{1}$, Christopher Love ${ }^{1,2}$, Zheng-Zhou Xu ${ }^{4}$, Peter L Molloy ${ }^{4}$, Ian T Jones ${ }^{5}$, Stephen McLaughlin ${ }^{6}$, Robyn L Ward ${ }^{7}$, Nicholas J Hawkins ${ }^{8}$, Andrew R Ruszkiewicz ${ }^{9}$, James Moore ${ }^{10}$, Antony W Burgess 2,3,11, Dana Busam ${ }^{12}$, Qi Zhao ${ }^{13}$, Robert L Strausberg ${ }^{13,14}$, Lara Lipton ${ }^{1,15}$, Jayesh Desai ${ }^{1,2,15}$, Peter Gibbs ${ }^{1,2,15}$ and Oliver M Sieber ${ }^{\star}, 1,2$

${ }^{1}$ Systems Biology and Personalised Medicine Division, Walter and Eliza Hall Institute of Medical Research, Parkville, VIC 3052, Australia; ${ }^{2}$ Faculty of Medicine, Dentistry and Health Sciences, Department of Medical Biology, University of Melbourne, Parkville, VIC 3010, Australia; ${ }^{3}$ Faculty of Medicine, Dentistry and Health Sciences, Department of Surgery, University of Melbourne, Parkville, VIC 3010, Australia; ${ }^{4}$ CSIRO Preventative Health Flagship, Animal, Food \& Health Sciences Division, North Ryde, NSW 2113, Australia; ${ }^{5}$ Department of Colorectal Surgery, Royal Melbourne Hospital, Parkville, VIC 3050, Australia; ${ }^{6}$ Department of Colorectal Surgery, Western Hospital, Footscray, VIC 3011, Australia; ${ }^{7}$ Lowy Cancer Research Centre, Prince of Wales Clinical School, University of New South Wales, Sydney, NSW 2052, Australia; ${ }^{8}$ School of Medical Sciences, University of New South Wales, Sydney, NSW 2052, Australia; ${ }^{9}$ Department of Surgical Pathology, SA Pathology, Adelaide, SA 5000, Australia; ${ }^{10}$ Department of Colorectal Surgery, Royal Adelaide Hospital, Adelaide, SA 5000, Australia; ${ }^{11}$ Structural Biology Division, Walter and Eliza Hall Institute of Medical Research, Parkville, VIC 3052, Australia; ${ }^{12} \mathrm{~J}$. Craig Venter Institute Rockville, MD, 20850, USA; ${ }^{13}$ Ludwig Collaborative Laboratory for Cancer Biology and Therapy, Department of Neurosurgery, Johns Hopkins University School of Medicine, Baltimore, MD 21231, USA; ${ }^{14}$ Ludwig Institute for Cancer Research Ltd., New York, NY 10017, USA and ${ }^{15}$ Department of Medical Oncology, Royal Melbourne Hospital, Parkville, VIC 3050, Australia

Background: APC mutations (APC-mt) occur in 70\% of colorectal cancers (CRCs), but their relationship to prognosis is unclear.

Methods: APC prognostic value was evaluated in 746 stage I-IV CRC patients, stratifying for tumour location and microsatellite instability (MSI). Microarrays were used to identify a gene signature that could classify APC mutation status, and classifier ability to predict prognosis was examined in an independent cohort.

Results: Wild-type APC microsatellite stable (APC-wt/MSS) tumours from the proximal colon showed poorer overall and recurrence-free survival (OS, RFS) than APC-mt/MSS proximal, APC-wt/MSS distal and APC-mt/MSS distal tumours (OS HR $\geqslant 1.79$, $P \leqslant 0.015$; RFS HR $\geqslant 1.88, P \leqslant 0.026$ ). APC was a stronger prognostic indicator than BRAF, KRAS, PIK3CA, TP53, CpG island methylator phenotype or chromosomal instability status $(P \leqslant 0.036)$. Microarray analysis similarly revealed poorer survival in MSS proximal cancers with an $A P C$-wt-like signature $(P=0.019)$. APC status did not affect outcomes in MSI tumours. In a validation on 206 patients with proximal colon cancer, APC-wt-like signature MSS cases showed poorer survival than APC-mt-like signature MSS or MSI cases (OS HR $\geqslant 2.50, P \leqslant 0.010$; RFS HR $\geqslant 2.14, P \leqslant 0.025$ ). Poor prognosis APC-wt/MSS proximal tumours exhibited features of the sessile serrated neoplasia pathway $(P \leqslant 0.016)$.

Conclusions: APC-wt status is a marker of poor prognosis in MSS proximal colon cancer.

${ }^{*}$ Correspondence: Dr OM Sieber; E-mail: Oliver.Sieber@wehi.edu.au
${ }^{16}$ These authors contributed equally to this work.

Received 21 May 2015; revised 8 July 2015; accepted 20 July 2015; published online 25 August 2015

(c) 2015 Cancer Research UK. All rights reserved 0007-0920/15 
Colorectal cancer (CRC) is a leading cause of cancer-related death in the Western world (Stewart and Wild, 2014). Despite advances in surgery and oncology, the average 5-year survival rate remains below $60 \%$. Treatment decisions are primarily based on disease staging performed by imaging and tumour histopathological assessment. However, there exists substantial heterogeneity in prognosis within tumours of identical stage.

Approximately $70 \%$ of sporadic CRCs are initiated by biallelic inactivation of the APC tumour-suppressor gene, resulting in aberrant activation of $\mathrm{WNT} / \beta$-catenin signalling (Christie et al, 2013). The majority of $A P C$-mutated (APC-mt) cancers are thought to develop via the classic adenoma-carcinoma pathway, characterised by premalignant adenomatous polyps with tubular and/or villous architecture, and carcinomas associated with TP53 mutation and chromosomal instability (CIN) (Fearon and Vogelstein, 1990). Another major pathway to CRC is the sessile serrated pathway, accounting for $15-20 \%$ of cases (Leggett and Whitehall, 2010; Snover, 2011; Bettington et al, 2013). This pathway is typified by precursor sessile serrated adenomas, wildtype $A P C$ (APC-wt), BRAF mutation, a CpG island methylator phenotype (CIMP-high), poor differentiation and mucinous histology, and approximately half of sessile serrated pathway cancers show late development of microsatellite instability (MSI). A further alternate pathway has been proposed, perhaps comprising $5-10 \%$ of CRC, which may arise from traditional serrated or tubulovillous adenomas and exhibits CIMP-low, KRAS and PIK3CA mutation and a microsatellite stable (MSS) genotype (Leggett and Whitehall, 2010; Day et al, 2013). Notably, these pathways show differential distributions throughout the large intestine, with the sessile serrated pathway more frequent in the proximal colon, and the classic pathway more common in the distal colon and rectum.

Individual molecular characteristics associated with the neoplasia pathways including CIN, MSI, CIMP and mutations in KRAS, $B R A F, P I K 3 C A$ and TP53 have all been evaluated as indicators of patient prognosis. Multiple studies have demonstrated good outcomes for early-stage cancers with MSI, and combined with data indicating that MSI cancers may not benefit from 5-FU-based chemotherapy, it has been proposed that moderate- and high-risk stage II patients exhibiting an MSI phenotype may forego adjuvant chemotherapy (Popat et al, 2005; Guastadisegni et al, 2010; Ng and Schrag, 2010). Conversely, there are emerging data that presence and extent of CIN are associated with inferior outcomes (Walther et al, 2008; Mouradov et al, 2013). Mutation in BRAF has been reported as an indicator of poor prognosis, in particular for patients with metastatic disease, but this relationship is complex, because of the strong positive association between BRAF mutation and MSI (Samowitz et al, 2005; French et al, 2008; Tie et al, 2011; Lochhead et al, 2013). Accordingly, recent data suggest that BRAF or KRAS mutation are associated with poor prognosis specifically in patients with MSS cancers (Phipps et al, 2015; Sinicrope et al, 2015). Evidence for the prognostic values of CIMP, PIK3CA and TP53 mutation is inconsistent (Munro et al, 2005; Russo et al, 2005; Prenen et al, 2010; Day et al, 2013).

Although mutations in APC have a principal role in CRC initiation, their relation to outcome remains unclear. Most previous studies have not found an association between the presence of APC mutation and prognosis, but these analysed small patient cohorts, only screened limited regions of the APC gene, and did not account for prognostically important features such MSI, CIN, BRAF mutation and tumour location (Dix et al, 1994; Løvig et al, 2002; Conlin et al, 2005; Hsieh et al, 2005; Meguid et al, 2008; Chen et al, 2009; Wong, 2010; Birnbaum et al, 2012)

Evaluation of $A P C$ prognostic value is further complicated by the observation that proximal and distal tumours differ substantially in their $A P C$ mutation spectra. In general, somatic $A P C$ mutations tend to cluster in codons 1282-1581, the so-called mutation cluster region, producing truncated proteins retaining 1-3 intact 20 amino-acid repeats (20AARs), functional domains that are critical for $\beta$-catenin regulation (Miyoshi et al, 1992; Christie et al, 2013). However, when analysed by tumour location, proximal cancers show a marked enrichment for mutations leaving 2-3 20AARs, while distal cancers show predominance of mutations leaving $0-1$ 20AARs, indicating distinct $\mathrm{WNT} / \beta$-catenin signalling thresholds for tumourigenesis in these embryologically distinct regions (Rowan et al, 2000; Albuquerque et al, 2002; Christie et al, 2013). A single prognostic study considered location of $A P C$ mutation and suggested that patients who have lost all $\beta$-catenin binding sites (15- and 20-AARs) of APC may have shorter cancerrelated survival than patients with mutations that have retained one or more binding sites (Løvig et al, 2002); however, this study did not consider tumour location.

Here, we examined whether APC mutation presence or genotype are indicators of patient prognosis when accounting for tumour location, MSI, CIN, CIMP, KRAS, BRAF, PIK3CA and TP53 status, analysing the largest CRC cohort $(n=746)$ to date in which the entire coding region of $A P C$ has been sequenced. We then identified the gene expression signature of $A P C$ mutation status using microarray analysis that could predict disease outcome. We validated the prognostic value of the $A P C$ classifier using an independent cohort of 206 patients from a publicly available microarray dataset (GSE39582) (Marisa et al, 2013) (Supplementary Figure 1).

\section{MATERIALS AND METHODS}

Patients. We analysed 746 patients with stages I-IV CRC who had undergone treatment at the Royal Melbourne Hospital (Parkville, VIC, Australia), Western Hospital Footscray (Footscray, VIC, Australia), Royal Adelaide Hospital (Adelaide, SA, Australia) and St Vincent's Hospital Sydney (Darlinghurst, NSW, Australia). Patients with familial polyposis syndromes, ulcerative colitis or Crohn's disease-associated CRC were excluded. All patients gave informed consent, and this study was human research ethics committee-approved (WEHI HREC 12/19). Clinicopathological characteristics and pre- and post-operative treatment details were collected using a multi-site database. Tumours from caecum to transverse colon were defined as proximal, and those from splenic flexure to rectum as distal. For patients with early stage disease (I-III), patient follow-up data were collected prospectively according to national guidelines, with 3-monthly clinic visits and testing for carcinoembryonic antigen levels, 12-monthly computed tomography scans of the chest, abdomen and pelvis for 2 years after diagnosis, and then 6-monthly clinic visits and carcinoembryonic antigen testing until 5 years from diagnosis. For patients with stage IV cancer, standard follow-up was with imaging every 8-9 weeks while patients remained on active therapy. Clinical follow-up while on active therapy was on a 4-weekly basis.

Mutation detection. Mutations in APC (entire coding region), KRAS (codons 12, 13 and 61), BRAF (V600E), PIK3CA (exons 9 and 20) and TP53 (exons 4 to 9) have been determined previously (Christie et al, 2013; Day et al, 2013). Briefly, DNA was extracted from macrodissected tumour and matched normal tissues, and Sanger sequencing performed in both orientations on a 3730xl DNA Analyzer (Applied Biosystems, Foster City, CA, USA). Any detected mutations were confirmed by resequencing of tumour and matched normal DNA from new PCR product.

Microsatellite instability, CIN and loss of heterozygosity assessment. Microsatellite instability status was defined using the Bethesda five-marker microsatellite panel (Boland et al, 1998). Microsatellite instability was considered present if instability was seen at $\geqslant 2$ markers. Tumour CIN status and loss of heterozygosity 
at $A P C$ have been determined previously using single nucleotide polymorphism microarray analysis (Human 610-Quad BeadChip, Illumina, San Diego, CA, USA) on tumour and matched normal DNA samples and OncoSNP software (Isis Innovations, Oxford, UK) (Yau et al, 2010; Christie et al, 2013; Mouradov et al, 2013).

CpG island methylator phenotype analysis. Tumour CIMP data have been reported based on MethyLight real-time PCR for the IGF2, SOCS1, RUNX3, CACNA1G and NGN1 marker panel, and the reference ALU (Day et al, 2013). Tumours with a percentage of methylated reference value of greater than 10 for $\geqslant 3$ CIMP markers were classified as CIMP-high (CIMP-H), those with 1-2 methylated markers as CIMP-low (CIMP-L), and 0 methylated markers as CIMP-0.

Microarray analysis. Gene expression profiles were determined for 52 MSS proximal colon cancers using the Affymetrix (Santa Clara, CA, USA) GeneChip Human Exon 1.0 ST Array version 2 according to the manufacturer recommendations. The microarray data have been deposited in the Gene Expression Omnibus database (GSE63624). Data were normalised using the Robust Multi-array Average algorithm (Irizarry et al, 2003) from the Affymetrix Power Tools software, the normalised data were log transformed (base 2) and adjusted for a batch effect using the ComBat algorithm (Johnson et al, 2007). Probe sets that were not expressed or probe sets that showed a low variability across samples were excluded. Expression values were required to be greater than the median of all expression measurements in at least $25 \%$ of samples, with an interquartile range across samples on the $\log 2$ scale of greater than 0.5 . Genes mapping to sex chromosomes were excluded because cases were not matched by gender. In addition, only probes for genes that were also represented on the Affymetrix GeneChip Human Genome U133 Plus 2.0 arrays were considered to enable cross-referencing across these platforms.

Gene signature for APC mutation status. The Limma algorithm (Smyth, 2004) was used to rank gene probes associated with $A P C$-wt status in our set of 52 MSS proximal colon cancers, with the top-ranked probe for each gene retained for classifier construction. We then identified the gene signature that could best classify $A P C$-wt status using a linear kernel nu-support vector machine (SVM) algorithm (Chang and Lin, 2001) and 10-fold cross-validation, evaluating sets of $2-100$ gene probes, selecting equal numbers of Limma top-ranked upregulated and downregulated candidates. The expression data were mean-centred and scaled to a mean of zero and a standard deviation of one for each gene probe entered into the algorithm. The significance of classification accuracy was evaluated using permutation testing. First, the accuracy of the optimised discriminating classifier was measured by 500 times repeated 10-fold cross-validation. Then, class labels of the samples were permutated 10000 times, obtaining a new signature and calculating the 10 -fold cross-validation accuracy for each permutated data set. Finally, the random chance of obtaining a signature with higher accuracy than the optimised discriminating classifier was determined.

Validation of prognostic capability of $A P C$ gene signature in an independent dataset. We validated the prognostic capability of the APC gene signature using a publicly available independent microarray dataset on stages I to IV CRCs (GSE39582) (Marisa et al, 2013). Raw data were Robust Multi-array Average normalised and batch-corrected using the ComBat algorithm, and restricted to proximal tumours with available outcome data $(n=206)$. For genes with multiple alternative probes, those with the largest variance across samples were selected. Gene probe data were mean-centred and scaled, and the SVM model used to predict $A P C$-wt status.
Statistical analysis. Statistical analyses were conducted using the statistical computing software R (The R Development Core Team, 2013). Differences between groups were assessed using the Kruskal-Wallis test for continuous variables and Fisher's exact test for categorical variables. Odds ratios (ORs) and 95\% confidence intervals (CI) were obtained from Fisher's exact test calculations. Outcome analyses were performed for overall survival (OS) and recurrence-free survival (RFS) from date of surgery, censored at 5 years. Patients who had received radiotherapy or were stage IV and had undergone additional surgery for metastases were excluded. Univariate survival distributions were compared using the log-rank test. Cox proportional hazards models were used to estimate survival distributions and hazard ratios for multivariate analyses, adjusting for gender, age at diagnosis, tumour stage and treatment; to facilitate comparisons between multiple $A P C$-wt/-mt tumour groups, hazard ratios were retrieved for all pairwise combinations of reference states. Comparisons between models with and without inclusion of specific molecular variables were made using the likelihood ratio test and the Aikake Information Criterion. Complete case analysis was used for all statistical calculations. Statistical analyses were two-sided and considered significant if $P<0.05$.

\section{RESULTS}

Clinicopathological and molecular features of CRC patients. In the cohort of 746 patients, the median age at presentation was 70 years and 55\% were male (Table 1 ). Seventy cancers were stage I, 229 stage II, 347 stage III and 100 stage IV; 315 were from the proximal colon, 242 from the distal colon and 189 from the rectum. Clinical follow-up information was available for 685 patients for OS. For patients with stages I-III CRC, RFS data were available for 415 cases. The median duration of follow-up was 47 months for OS, and 37 months for RFS. Among the 685 patients with available outcome data, 296 had received standard adjuvant 5-fluorouracil-based chemotherapy (unknown in 33 cases).

The cancers had molecular features that were similar to those found in other studies (Table 1). Truncating APC mutations were detected in $68.4 \%$ (510 of 746) of tumours, and 31.1\% (201 of 627 with available single nucleotide polymorphism array data) showed loss of heterozygosity at APC. Among the APC-mt cases, $76.7 \%$ (335 of 437) had two hits ( 2 mutations or 1 mutation and loss of heterozygosity). The frequencies of mutations in $B R A F, K R A S$, PIK3CA and TP53 were 9.0\% (67 of 746), 35.1\% (262 of 746), $12.5 \%$ (93 of 746 ) and $55.4 \%$ (413 of 746), respectively; $73.6 \%$ (465 of 632) of tumours were CIN, $13.4 \%$ (100 of 746) MSI, $17.3 \%$ (85 of 491) CIMP-H and 21.8\% (107 of 491) CIMP-L. We confirmed the established pairwise associations between MSI, CIN and specific gene mutations. Microsatellite instability displayed a strong direct association with $B R A F$ mutation $(\mathrm{OR}=13.0)$, and a strong inverse association with TP53 mutation $(\mathrm{OR}=0.34)$, while CIN showed the opposite associations $(\mathrm{CIN} / B R A F$ OR $=0.20$; CIN/TP53 $\mathrm{OR}=7.8)$. KRAS and $B R A F$ mutations were mutually exclusive $(\mathrm{OR}=0)$, while $K R A S$ mutation exhibited positive associations with PIK3CA mutation $(\mathrm{OR}=2.4)$ and CIMP-L $(\mathrm{OR}=1.8$ as compared with CIMP-0) $(P<0.012$ for all comparisons).

Proximal APC-wt/MSS tumours exhibit inferior prognosis. We tested whether overall $A P C$ mutation status (wild-type $v s$ mutated) was associated with patient prognosis when accounting for tumour MSI status and location, and adjusting for gender, age at diagnosis, tumour stage and treatment. Among patients with MSS tumours, $A P C$-wt proximal cancers showed significantly inferior prognosis as compared with $A P C$-mt proximal, $A P C$-wt distal and $A P C$-mt distal cancers for OS and RFS (OS HR $\geqslant 1.79, P \leqslant 0.015$; RFS $\mathrm{HR} \geqslant 1.88, P \leqslant 0.026$ ) (Figure 1 , Table $2 \mathrm{~A}$ ), and this was retained 
Table 1. Characteristics of 746 patients with colorectal cancer according to $A P C$ mutation status

\begin{tabular}{|c|c|c|c|c|}
\hline & & $A P C$-wt & $A P C-\mathrm{mt}$ & \\
\hline & $n=746$ & $236(31.6)$ & $510(68.4)$ & $P$ \\
\hline Age, years & 744 & 235 & 509 & \\
\hline Mean \pm s.d. & $69.1 \pm 11.3$ & $69.6 \pm 11.7$ & $68.9 \pm 11.2$ & 0.317 \\
\hline Median & 70 & 70 & 70 & \\
\hline Range & $25.0-99.0$ & $25.0-99.0$ & $33.0-93.0$ & \\
\hline Unknown & 2 & & & \\
\hline Sex & 746 & 236 & 510 & \\
\hline Male & $413(55.4)$ & $109(26.4)$ & $304(73.6)$ & $<0.001^{*}$ \\
\hline Female & $333(44.6)$ & $127(38.1)$ & 206 (61.9) & \\
\hline Stage & 746 & 236 & 510 & \\
\hline 1 & $70(9.4)$ & $15(21.4)$ & $55(78.6)$ & 0.080 \\
\hline ॥ & $229(30.7)$ & $67(29.3)$ & $162(70.7)$ & \\
\hline III & 347 (46.5) & $124(35.7)$ & $223(64.3)$ & \\
\hline IV & $100(13.4)$ & $30(30.0)$ & $70(70.0)$ & \\
\hline Site & 746 & 236 & 510 & \\
\hline Right Colon & $315(42.2)$ & 131 (41.6) & $184(58.4)$ & $<0.001^{\star}$ \\
\hline Left colon & 242 (32.4) & 51 (21.1) & 191 (78.9) & \\
\hline Rectum & $189(25.3)$ & $54(28.6)$ & $135(71.4)$ & \\
\hline Differentiation & 718 & 221 & 497 & \\
\hline $\begin{array}{l}\text { Well/ } \\
\text { Moderate }\end{array}$ & $596(83.0)$ & $162(27.2)$ & $434(72.8)$ & $<0.001^{*}$ \\
\hline Poor & $122(17.0)$ & $59(48.4)$ & $63(51.6)$ & \\
\hline Unknown & 28 & 15 & 13 & \\
\hline Mucinous & 737 & 231 & 506 & \\
\hline No & 577 (78.3) & $154(26.7)$ & $423(73.3)$ & $<0.001^{*}$ \\
\hline Yes & $160(21.7)$ & 77 (48.1) & 83 (51.9) & \\
\hline Unknown & 9 & 5 & 4 & \\
\hline MSI status & 746 & 236 & 510 & \\
\hline MSS & $646(86.6)$ & 167 (25.9) & 479 (74.1) & $<0.001^{*}$ \\
\hline MSI & $100(13.4)$ & 69 (69.0) & 31 (31.0) & \\
\hline CIMP status & 491 & 140 & 351 & \\
\hline CIMPO & 299 (60.9) & 55 (18.4) & $244(81.6)$ & $<0.001^{*}$ \\
\hline CIMPL & $107(21.8)$ & $25(23.4)$ & $82(76.6)$ & \\
\hline $\mathrm{CIMPH}$ & 85 (17.3) & $60(70.6)$ & $25(29.4)$ & \\
\hline Unknown & 255 & 96 & 159 & \\
\hline BRAF & 746 & 236 & 510 & \\
\hline No & 679 (91.0) & $183(27.0)$ & $496(73.0)$ & $<0.001^{*}$ \\
\hline Yes & $67(9.0)$ & $53(79.1)$ & $14(20.9)$ & \\
\hline KRAS & 746 & 236 & 510 & \\
\hline No & 484 (64.9) & $185(38.2)$ & 299 (61.8) & $<0.001^{*}$ \\
\hline Yes & $262(35.1)$ & $51(19.5)$ & $211(80.5)$ & \\
\hline PIK3CA & 746 & 236 & 510 & \\
\hline No & $653(87.5)$ & 214 (32.8) & $439(67.2)$ & 0.095 \\
\hline Yes & $93(12.5)$ & $22(23.7)$ & $71(76.3)$ & \\
\hline TP53 & 746 & 236 & 510 & \\
\hline No & $333(44.6)$ & $143(42.9)$ & $190(57.1)$ & $<0.001^{*}$ \\
\hline Yes & $413(55.4)$ & 93 (22.5) & $320(77.5)$ & \\
\hline CIN status & 632 & 191 & 441 & \\
\hline $\mathrm{CIN}-$ & $167(26.4)$ & $86(51.5)$ & $81(48.5)$ & $<0.001^{\star}$ \\
\hline $\mathrm{CIN}+$ & 465 (73.6) & 105 (22.6) & $360(77.4)$ & \\
\hline Unknown & 114 & 45 & 69 & \\
\hline
\end{tabular}

when restricted to stage II and III cancers (OS $\mathrm{HR} \geqslant 1.79$, $P \leqslant 0.029$; RFS $H R \geqslant 1.81, P \leqslant 0.038$ ) (Supplementary Table $1 \mathrm{~A}$ ). Accordingly, a multivariate model with an APC-tumour location interaction term provided a significantly better fit of the survival data as compared with a model with $A P C$ status and tumour location but without the interaction term (OS, $P=0.043$; RFS, $P=0.011$, likelihood ratio test). We found no evidence for differential outcomes between APC-mt/MSS proximal, APC-wt/ MSS distal and APC-mt/MSS distal tumours (Figure 1, Table 2A, Supplementary Table 1A for stage II and III cancers).

No prognostic value of APC mutation in MSI tumours. Among patients with MSI cancers, testing for association between $A P C$ mutation status and prognosis was restricted to proximal cases owing to the low prevalence of MSI in distal tumours $(n=16)$. In contrast to MSS proximal cancers, the adverse prognostic influence of $A P C$-wt status was lost in MSI proximal cancers $(n=75)$ with similar OS and RFS for wild-type and mutated tumours (multivariate $\mathrm{OS}, P=0.859$; RFS, $P=0.779$, Figure 1 , Table $2 \mathrm{~B}$, Supplementary Table 1B for stage II and III cancers).

Compared with MSI proximal cancers, $A P C$-wt/MSS proximal tumours showed significantly poorer survival $(\mathrm{OS}, \mathrm{HR}=2.05$, $P=0.022$; RFS, $\mathrm{HR}=3.34, P=0.005$ ). Microsatellite instability proximal tumours further exhibited a trend to improved outcomes as compared with $A P C$-mt/MSS proximal cancers, although this was not statistically significant ( $\mathrm{OS}, \mathrm{HR}=0.88, P=0.656$; RFS, $\mathrm{HR}=0.59, P=0.185)($ Figure $2 \mathrm{~A}$, Table $3 \mathrm{~A}$ ). These trends were retained when restricting the analysis to stage II and III cancers (Supplementary Table 2A).

APC mutation genotype does not provide additional prognostic information. Given the different APC mutation spectra in proximal and distal tumours (Albuquerque et al, 2010; Christie et al, 2013), we examined whether classification of tumours by $A P C$ mutation genotype had additional prognostic value. Among patients with $A P C$-mt/MSS cancers, outcomes were similar across tumour locations irrespective of whether truncating APC mutations left 0 or $\geqslant 1$ 15AARs required for $\beta$-catenin binding, or whether the mutations left $0-1$ or 2-3 20AARs associated with residual $\beta$-catenin binding/regulatory activity $(P \geqslant 0.169$ for all comparisons, Supplementary Table $3 \mathrm{~A}$ and B). Further, no outcome differences were apparent when considering the number of hits in $A P C$ with one exception: proximal tumours with 1 hit in $A P C$ showed a tendency to better OS as compared with distal tumours with 1 hit in $A P C(\mathrm{HR}=0.37, P=0.049)$, however, this trend was not observed for RFS $(P=0.246$; Supplementary Table 3C). We did not explore APC genotypes in MSI CRCs owing to low sample numbers per group.

$A P C$ prognostic value in the context of other molecular changes. The prognostic value of APC status in proximal MSS tumours was evaluated against other molecular changes. Singlevariable models with BRAF, CIN, CIMP-H, KRAS, PIK3CA or TP53 status were compared with models with addition of APC status and vice versa using the likelihood ratio test. In all comparisons, $A P C$ mutation was found to be the strongest indicator of outcome: addition of APC status significantly improved all OS and RFS models with CIMP, BRAF, KRAS, PIK3CA or TP53 or CIN status ( $P \leqslant 0.036$ for all comparisons), whereas addition of the latter molecular variables to models with $A P C$ status did not significantly improve model fit (Table 4). Accordingly, direct comparison of models with either APC mutation or the relevant molecular feature of interest using the Akaike Information Criterion favoured the model with the APC mutation in all cases (Table 4).

APC gene signature in MSS proximal tumours. For 52 patients with MSS proximal colon cancer, including $35 \mathrm{APC}$-mt patients, we were able to obtain sufficient tumour RNA of high quality for 

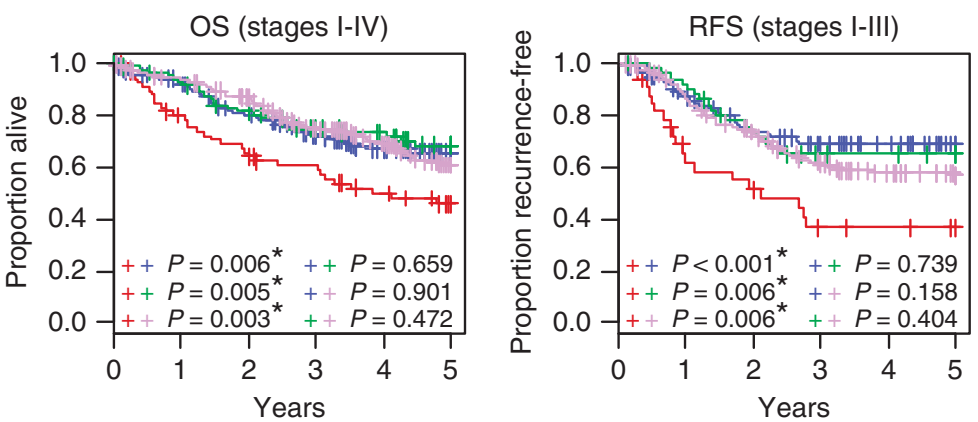

Number at risk

\begin{tabular}{lcccccc}
$A P C$-wt/Prox & 67 & 50 & 41 & 35 & 26 & 18 \\
$A P C$-mt/Prox & 153 & 133 & 111 & 89 & 65 & 40 \\
$A P C$-wt/Dist & 84 & 75 & 64 & 54 & 47 & 32 \\
$A P C$-mt/Dist & 283 & 256 & 225 & 179 & 145 & 103 \\
\multicolumn{1}{c}{ APC-wt/Prox } & \multicolumn{4}{c}{ APC-mt/Prox }
\end{tabular}

B

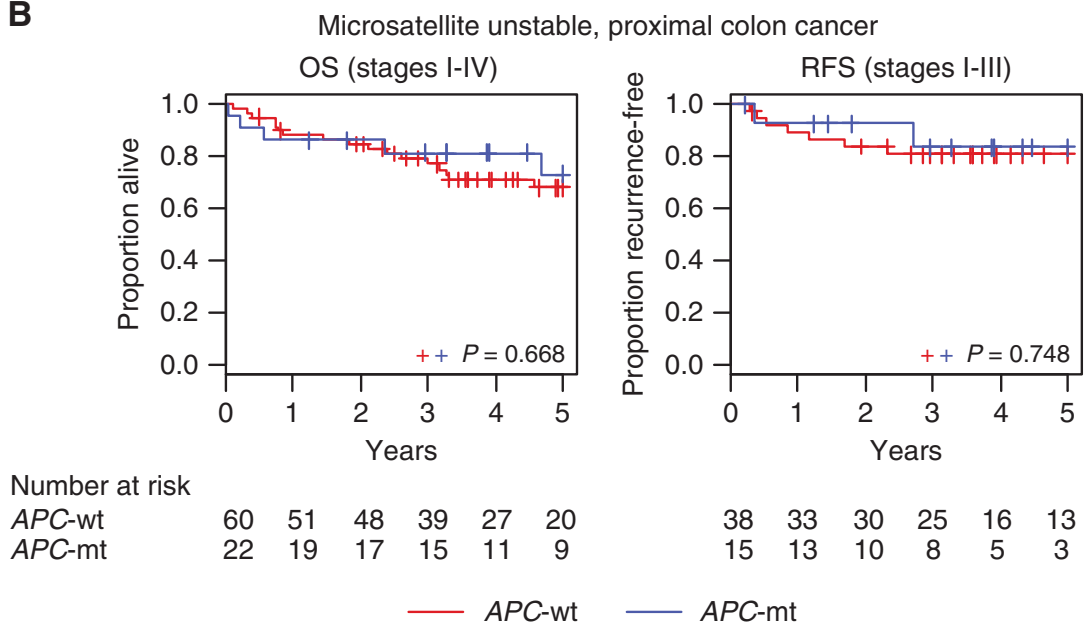

Figure 1. Kaplan-Meier curves of OS and RFS (A) for patients with MSS colorectal cancer, and (B) for patients with MSI proximal colon cancer, according to APC mutation status and tumour location. Abbreviations: Dist, distal; Prox, proximal.

microarray analysis. Using class-comparison analysis, we ranked genes by significance of differential expression between $A P C$-wt and $A P C$-mt patients. A SVM with 10 -fold cross-validation was used to identify the gene signature that could best classify $A P C$-wt status, with a classifier comprising the top-ranked 18 upregulated and 18 downregulated gene probes achieving the highest crossvalidation prediction accuracy (95.8\%) (Supplementary Figure 2, Supplementary Table 4). Using these 36 discriminating genes, twoway clustering and principal component analysis separated $A P C$-wt and $A P C$-mt patients (Supplementary Figure 3). To further evaluate the SVM model, we re-trained the model using 10000 random permutations of the APC mutation data. None of these permutations yielded equal or superior 10-fold crossvalidation prediction accuracy to that of the trained model, yielding a false discovery rate less than $10^{-4}$. $A P C$-wt gene signature tumours exhibited statistically significantly worse survival than $A P C$-mt gene signature tumours, as was observed when considering $A P C$ mutation status determined by Sanger sequencing (Supplementary Figure 4).

Validation of prognostic capability of $A P C$-wt gene signature in an independent cohort of proximal colon cancers. We applied the $A P C$-wt gene signature to an independent microarray dataset on 206 stage I-IV proximal colon cancers by Marisa et al (2013) (GSE39582). Consistent with findings in our cohort, patients with $A P C$-wt-like gene signature MSS tumours showed significantly poorer OS and RFS than those with $A P C$-mt-like gene signature MSS tumours and MSI tumours (OS HR $\geqslant 2.50, P \leqslant 0.010$; RFS $\mathrm{HR} \geqslant 2.14, \quad P \leqslant 0.025$ ) (Figure $2 \mathrm{~B}$, Table $3 \mathrm{~B}$, Supplementary Table $2 \mathrm{~B}$ when restricting to stage II and III cancers). There was no significant difference in outcome by $A P C$ class for MSI cancers $(P \geqslant 0.375$ for OS and RFS).

Proximal $A P C$-wt/MSS tumours exhibit features of the sessile serrated pathway. Given the differences in prognosis among MSS CRCs by APC status and tumour location, we tested whether these were reflected at the pathological and molecular level. In pairwise comparisons between tumour groups (Figure 3, Supplementary Table 5), the poor prognosis APC-wt/MSS cancers of the proximal colon $(n=70)$ consistently showed associations with features of the sessile serrated pathway including poor differentiation, CIMP-H and $B R A F$ mutation ( $P \leqslant 0.016$ for all comparisons), and to a lesser extent mucinous histology $(P \leqslant 0.058)$ and female gender $(P \leqslant 0.085$, Figure $3 \mathrm{~A})$. APC-mt/MSS distal cancers $(n=318)$ displayed the expected classic adenoma-carcinoma pathway features such as TP53 mutation and CIN $(P \leqslant 0.020$ for all comparisons, Figure 3D), while APC-mt/MSS proximal cancers $(n=161)$ showed association with KRAS mutation $(P<0.001$ for all comparisons) and to a lesser extent with PIK3CA mutation ( $P \leqslant 0.054$ for all comparisons), hallmarks of the alternate pathway (Figure 3B). APC-wt/MSS distal cancers $(n=97)$ showed no consistently outstanding characteristics, although some tendency 
Table 2A. Cox proportional-hazards analyses of OS and RFS (A) for patients with microsatellite stable (MSS) colorectal cancer, and (B) for patients with microsatellite unstable (MS) proximal colon cancer, according to APC mutation status and tumour location; (2A) Microsatellite stable (MSS) colorectal cancer

\begin{tabular}{|c|c|c|c|c|}
\hline & \multicolumn{2}{|c|}{ Overall survival } & \multicolumn{2}{|c|}{ Recurrence-free survival } \\
\hline & $\mathrm{HR}(95 \% \mathrm{Cl})$ & $P$ & HR $(95 \% \mathrm{Cl})$ & $P$ \\
\hline $\begin{array}{l}\text { APC-wt/Prox vs } \\
\text { APC-mt/Prox }\end{array}$ & $1.79(1.12-2.85)$ & $0.015^{\star}$ & $1.99(1.08-3.65)$ & $0.026^{*}$ \\
\hline $\begin{array}{l}\text { APC-wt/Prox vs } \\
\text { APC-wt/Dist }\end{array}$ & $2.01(1.17-3.43)$ & $0.011^{*}$ & $2.71(1.39-5.28)$ & $0.003^{*}$ \\
\hline $\begin{array}{l}\text { APC-wt/Prox vs } \\
\text { APC-mt/Dist }\end{array}$ & $1.84(1.22-2.78)$ & $0.004^{*}$ & $1.88(1.13-3.15)$ & $0.016^{*}$ \\
\hline $\begin{array}{l}\text { APC-mt/Prox vs } \\
A P C-w t / D i s t\end{array}$ & $1.12(0.67-1.87)$ & 0.655 & $1.36(0.73-2.54)$ & 0.329 \\
\hline $\begin{array}{l}\text { APC-mt/Prox vs } \\
\text { APC-mt/Dist }\end{array}$ & $1.03(0.71-1.49)$ & 0.876 & $0.95(0.60-1.50)$ & 0.814 \\
\hline $\begin{array}{l}\text { APC-wt/Dist vs } \\
\text { APC-mt/Dist }\end{array}$ & $0.92(0.58-1.45)$ & 0.710 & $0.69(0.40-1.19)$ & 0.186 \\
\hline Age (Decades) & $1.32(1.12-1.55)$ & $<0.001^{\star}$ & $0.93(0.79-1.09)$ & 0.386 \\
\hline $\begin{array}{l}\text { Gender (Female } \\
\text { vs Male) }\end{array}$ & $0.77(0.57-1.04)$ & 0.089 & $0.66(0.46-0.95)$ & $0.024^{*}$ \\
\hline Stage II vs I & $1.03(0.46-2.30)$ & 0.938 & $1.88(0.54-6.50)$ & 0.320 \\
\hline Stage III vs I & $3.33(1.56-7.10)$ & $0.002^{\star}$ & $9.23(2.78-30.65)$ & $<0.001^{*}$ \\
\hline Stage IV vs I & $9.62(4.33-21.36)$ & $<0.001 *$ & & \\
\hline $\begin{array}{l}\text { Chemotherapy } \\
\text { (Yes vs No) }\end{array}$ & $0.82(0.57-1.17)$ & 0.270 & $0.68(0.43-1.09)$ & 0.107 \\
\hline Events/N & $189 / 561$ & & $129 / 351$ & \\
\hline $\begin{array}{l}\text { Abbreviations: } \mathrm{Cl}= \\
\text { survival; Prox }=\text { prox } \\
\text { APC wild-type/mut } \\
\text { combinations of ref }\end{array}$ & $\begin{array}{l}\text { onfidence interval; } \\
\text { al; RFS = recurrence- } \\
\text { d tumour groups, } \\
\text { nce states. }\end{array}$ & & $\mathrm{HR}=$ hazard ratio; & \\
\hline
\end{tabular}

Table 2B. (B) Microsatellite unstable (MSI) proximal colon cancer

\begin{tabular}{|c|c|c|c|c|}
\hline & \multicolumn{2}{|c|}{ Overall survival } & \multicolumn{2}{|c|}{ Recurrence-free survival } \\
\hline & HR $(95 \% \mathrm{Cl})$ & $P$ & HR $(95 \% \mathrm{Cl})$ & $P$ \\
\hline $\begin{array}{l}A P C \text {-wt v } \\
A P C-m t\end{array}$ & $0.90(0.27-2.96)$ & 0.859 & $1.26(0.25-6.50)$ & 0.779 \\
\hline Age (Decades) & $2.37(1.30-4.34)$ & $0.005^{*}$ & $0.95(0.40-2.25)$ & 0.900 \\
\hline $\begin{array}{l}\text { Gender (Female } \\
\text { vs Male) }\end{array}$ & $1.06(0.31-3.59)$ & 0.924 & $1.58(0.32-7.80)$ & 0.576 \\
\hline Stage III vs $\mid / \|^{a}$ & $0.95(0.31-2.90)$ & 0.933 & $3.36(0.62-18.30)$ & 0.161 \\
\hline Stage IV vs $\mid / \|^{a}$ & $5.54(0.38-81.75)$ & 0.213 & & \\
\hline $\begin{array}{l}\text { Chemotherapy } \\
\text { (Yes vs No) }\end{array}$ & $2.10(0.47-9.37)$ & 0.330 & $0.25(0.03-1.99)$ & 0.189 \\
\hline Events/N & $17 / 75$ & & 9/53 & \\
\hline
\end{tabular}

towards features of the sessile serrated pathway was noted when compared with $A P C$-mt/MSS distal cancers (mucinous histology, CIMP-H and BRAF mutation; $P \leqslant 0.009$ for all comparisons). However, these differences were much less pronounced than for MSS/APC-wt proximal cancers (Figure 3C).

In contrast, among good prognosis MSI proximal cancers $(n=82)$, for which the APC prognostic value was attenuated, no significant differences were apparent by $A P C$ status (Supplementary Table 6). When MSI proximal cancers were compared with the four groups of MSS cancers, these most closely resembled the poor prognosis $A P C$-wt/MSS proximal group, exhibiting an overrepresentation of sessile serrated pathway features such as female gender, CIMP-H, BRAF mutation, poor differentiation and mucinous histology (Figure 3E, Supplementary Table 5). However, MSI proximal cancers differed from all four groups in showing little CIN and a tendency to present at earlier tumour stages. Associations for MSI distal cancers were not investigated owing to the small sample size $(n=16)$.

\section{DISCUSSION}

Prognostic, pathological and molecular features of CRC, including $A P C$ mutation spectra, are well-established to differ between proximal and distal tumours and between MSS and MSI cases (Meguid et al, 2008; Albuquerque et al, 2010; Wong, 2010; Sinicrope and Sargent, 2012; Christie et al, 2013). In this study, the largest survey of the prognostic value of $A P C$ mutation to date, we have found evidence that $A P C$ status shows differential outcome associations across these tumour subgroups: $A P C$-wt/MSS proximal tumours had inferior OS and RFS as compared with APC-mt/ MSS proximal, $A P C$-wt/MSS distal and $A P C$-mt/MSS distal tumours, which showed similar outcomes. The prognostic value of APC mutation was lost in the MSI tumours of the proximal colon, which had the most favourable prognosis overall. Notably, attenuation of marker prognostic value in MSI cancers has previously been reported for BRAF mutation and CIMP (Ward et al, 2003; Samowitz et al, 2005; Ogino et al, 2012). Poor prognosis of $A P C$-wt/MSS proximal tumours was validated in an independent patient cohort (Marisa et al, 2013) using a predictor of $A P C$-wt status from microarray expression data. Most previous studies evaluating APC mutation status have not identified a relationship with prognosis (Dix et al, 1994; Conlin et al, 2005; Hsieh et al, 2005; Chen et al, 2009; Birnbaum et al, 2012). However, these studies did not consider CRC groups by tumour location and MSI status, likely precluded by their smaller sample sizes $(n=100-218)$, and only performed mutation screening for limited regions of the APC gene. These differences in study design and size would have reduced the power to detect tumoursubgroup-specific outcome associations.

Differences in tumour prognostic behaviours by APC mutation, location and MSI status were strongly supported by differences at the pathological and molecular level (Supplementary Figure 5). The poor prognosis $A P C$-wt/MSS proximal cancers were specifically associated with characteristics of the sessile serrated neoplasia pathway including female gender, poor differentiation, mucinous histology, CIMP-H and BRAF mutation (Leggett and Whitehall, 2010; Snover, 2011; Bettington et al, 2013, 2014). In contrast, $A P C$-mt/MSS proximal cancers showed features of the alternate pathway (KRAS and PIK3CA mutation) (Leggett and Whitehall, 2010; Day et al, 2013). APC-mt/MSS distal cancers showed features of the classic adenoma-carcinoma pathway (TP53 mutation and CIN) (Fearon and Vogelstein, 1990), whereas APC-wt/MSS distal cancers had no consistently outstanding features. CpG island methylator phenotype- $\mathrm{L}$, which has been associated with the alternate pathway in some studies (Leggett and Whitehall, 2010), was not overrepresented in APC-mt/MSS proximal cancers, although a positive association between CIMP-L and KRAS mutation was apparent for the entire cohort.

Among MSI cancers of the proximal colon, for which the prognostic value of $A P C$ mutation was attenuated, pathological and molecular features accordingly also did not differ by APC status. Overall, MSI proximal cancers showed the expected serrated pathway features (female gender, poor differentiation, mucinous histology, CIMP-H and BRAF mutation), similar to the poor prognosis proximal $A P C$-wt/MSS group, but differed in showing little CIN and presentation at earlier tumour stages. 
A

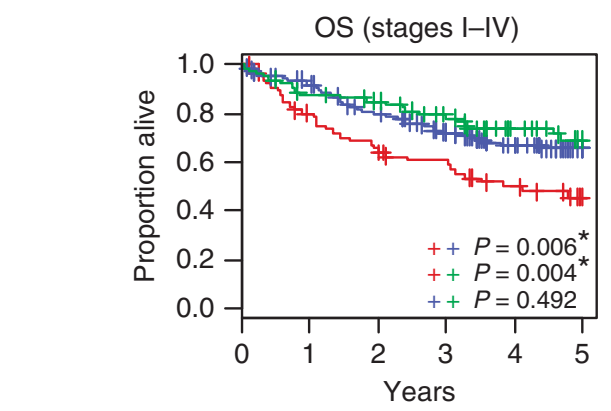

Number at risk

APC-wt/MSS

MSI

$\begin{array}{cccccc}67 & 50 & 41 & 35 & 26 & 18 \\ 153 & 133 & 111 & 89 & 65 & 40 \\ 82 & 70 & 65 & 54 & 38 & 29\end{array}$

Discovery cohort

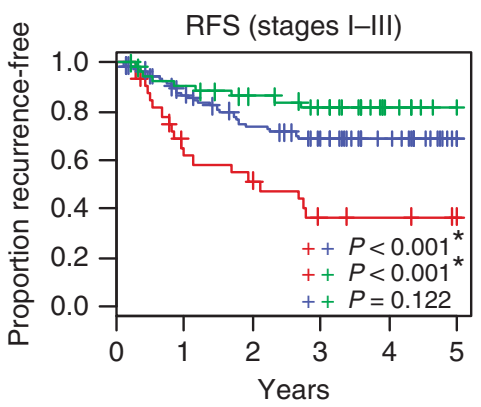

$\begin{array}{llllll}33 & 18 & 15 & 9 & 8 & 6\end{array}$

$\begin{array}{llllll}97 & 77 & 62 & 51 & 39 & 24\end{array}$

$\begin{array}{llllll}53 & 46 & 40 & 33 & 21 & 16\end{array}$

- $A P C$-wt/MSS $-A P C$-mt/MSS MSI

B

Validation cohort
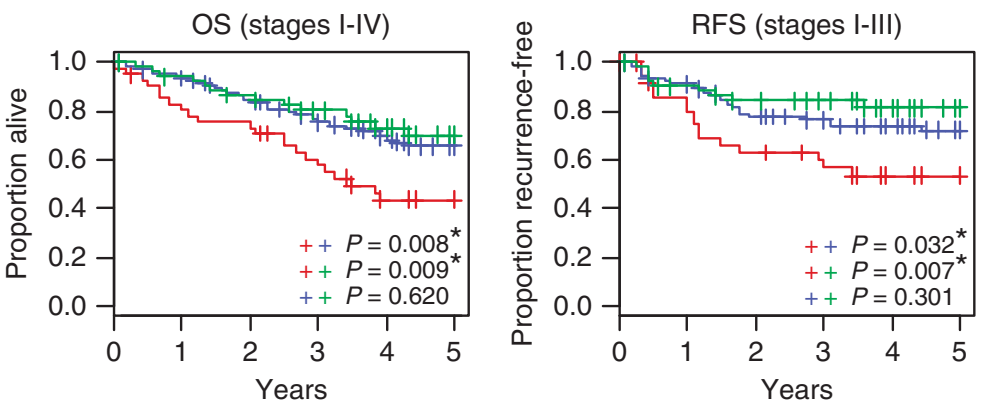

Number at risk

$\begin{array}{lllllll}A P C \text {-mt-like/MSS } & 42 & 34 & 31 & 23 & 14 & 12\end{array}$

APC-wt-like/MSS $110 \quad 102 \quad 86 \quad \begin{array}{lllll}110 & 57 & 42\end{array}$

$\begin{array}{lllllll}\text { MSI } & 54 & 49 & 44 & 36 & 27 & 17\end{array}$

$\begin{array}{llllll}38 & 30 & 22 & 19 & 13 & 11 \\ 95 & 85 & 68 & 60 & 48 & 36\end{array}$

$\begin{array}{llllll}53 & 45 & 40 & 34 & 24 & 15\end{array}$

- $A P C$-mut-like/MSS

APC-wt-like/MSS

MSI

Figure 2. Kaplan-Meier curves of OS and RFS (A) for patients with proximal colon cancer, according to APC mutation and microsatellite instability status (discovery cohort), and (B) for patients with proximal colon cancer, according to APC gene signature and microsatellite instability status (validation cohort, GSE39582 (Marisa et al, 2013)). Abbreviations: MSS/MSI, microsatellite stable/unstable.

The prognostic value of APC mutation status in MSS proximal cancers was not explained by correlation with other tumour molecular features such as CIN, CIMP, BRAF, KRAS, PIK3CA or TP53 status. This is particularly notable for CIN, BRAF and KRAS mutation, which have been linked to inferior prognosis in MSS tumours (Tie et al, 2011; Pai et al, 2012; Lochhead et al, 2013; Sinicrope et al, 2015). Instead, our data suggest a more general association between tumour sessile serrated pathway features and poor prognosis, which is supported by recent gene expressionbased studies. Using microarray analysis to create a gene expression classifier for BRAF-mutated CRCs, Popovici et al (2012) identified a group of cancers including but not restricted to $B R A F$-mutated tumours which showed poor prognosis, proximal location and mucinous histology, consistent with serrated pathway characteristics. Similarly, De Sousa et al (2013) used multiple microarray datasets to identify a CRC subgroup displaying a sessile serrated adenoma-like gene expression signature and inferior prognosis as compared with cancers with MSI- or CIN-associated signatures. A recent molecular profiling study has further reported poor prognosis for MSS or MSI-low, CIMP-positive, BRAF mutated, KRAS wild-type CRCs, which likely have significant overlap with the $A P C$-wt/MSS proximal subtype defined in our study (Phipps et al, 2015).

Methylation at the APC promoter resulting in gene silencing has been suggested as a potential alternative mechanism to APC mutation (Arnold et al, 2004). Using DNA methylation array and
RNA-Seq data for 215 CRCs reported by The Cancer Genome Atlas Network, neither promoter hypermethylation nor reduced gene expression were inversely associated with $A P C$ mutation when considering all cases or the subset of MSS proximal cancers (Supplementary Figure 6) (Network TCGA, 2012). These results are consistent with our previous observation that $A P C$ promoter hypermethylation does not substitute for truncating mutations (Segditsas et al, 2008).

Interestingly, AXIN2 and RNF43 were the most differentially expressed genes by APC mutation status in proximal MSS tumours, with both showing reduced expression in the $A P C$-wt tumours. AXIN2 is a component of the central $\beta$-catenin destruction complex, while RNF43 is a transmembrane E3 ligase involved in removing WNT receptors from the cell surface (Jho et al, 2002; de Lau et al, 2014). AXIN2 and RNF43 are themselves WNT target genes and constitute negative WNT feedback loops, suggesting that their downregulation may be an alternative to $A P C$ mutation causing aberrant WNT pathway activation. AXIN2 and RNF43 are frequently mutated in MSI CRCs (Liu et al, 2000; Giannakis et al, 2014), and AXIN2 silencing by promoter hypermethylation has been observed in MSI cancers and sessile serrated adenomas (Muto et al, 2014). Furthermore, AXIN2 and RNF43 were found in the Popovici et al (2012) signature for BRAF-mutated CRC and the De Sousa et al (2013) gene signatures for CRC classification.

It has been suggested that $A P C$-mutated cancers may show differential outcomes depending on mutation location within the 
gene, with patients who have lost all $\beta$-catenin binding sites having shorter cancer-related survival than patients who have retained one or more binding sites (Løvig et al, 2002). We did not find evidence of outcome differences by the number of intact $\beta$-catenin binding

Table 3A. Cox proportional-hazards analyses of OS and RFS (A) for patients with proximal colon cancer, according to APC mutation status and microsatellite instability (discovery cohort), and (B) for patients with proximal colon cancer, according to APC gene signature and microsatellite instability (validation cohort, GSE39582 (Marisa et al, 2013)); (A) Discovery cohort

\begin{tabular}{|c|c|c|c|c|}
\hline & \multicolumn{2}{|c|}{ Overall survival } & \multicolumn{2}{|c|}{ Recurrence-free survival } \\
\hline & $\mathrm{HR}(95 \% \mathrm{Cl})$ & $P$ & HR (95\% Cl) & $P$ \\
\hline $\begin{array}{l}\text { MSI vs APC-mt/ } \\
\text { MSS }\end{array}$ & $0.88(0.49-1.57)$ & 0.656 & $0.59(0.27-1.29)$ & 0.185 \\
\hline $\begin{array}{l}\text { APC-wt/MSS/ } \\
\text { vs MSI }\end{array}$ & $2.05(1.11-3.77)$ & $0.022^{*}$ & $3.34(1.45-7.68)$ & $0.005^{\star}$ \\
\hline $\begin{array}{l}A P C-w t / M S S \text { vs } \\
A P C-\mathrm{mt} / \mathrm{MSS}\end{array}$ & $1.79(1.11-2.88)$ & $0.016^{*}$ & $1.97(1.06-3.63)$ & $0.031^{*}$ \\
\hline Age (Decades) & $1.41(1.09-1.82)$ & $0.009^{*}$ & $1.08(0.81-1.45)$ & 0.588 \\
\hline $\begin{array}{l}\text { Gender (Female } \\
\text { vs Male) }\end{array}$ & $0.92(0.60-1.42)$ & 0.718 & $0.93(0.54-1.60)$ & 0.794 \\
\hline Stage II vs I & $1.85(0.43-8.06)$ & 0.412 & $1.19(0.25-5.68)$ & 0.824 \\
\hline Stage III vs I & $5.04(1.16-21.82)$ & $0.030 *$ & $5.84(1.26-27.04)$ & $0.024^{\star}$ \\
\hline Stage IV vs I & $19.21(4.25-86.76)$ & $<0.001^{\star}$ & & \\
\hline $\begin{array}{l}\text { Chemotherapy } \\
\text { (Yes vs No) }\end{array}$ & $1.03(0.60-1.76)$ & 0.919 & $0.91(0.44-1.88)$ & 0.807 \\
\hline Events/N & $91 / 282$ & & $55 / 182$ & \\
\hline \multicolumn{5}{|c|}{$\begin{array}{l}\text { Abbreviations: } \mathrm{Cl}=\text { confidence interval; } \mathrm{HR}=\text { hazard ratio; } \mathrm{MSI}=\text { microsatellite instability; } \\
\mathrm{MSS}=\text { microsatellite stable; } \mathrm{OS}=\text { overall survival; } \mathrm{RFS}=\text { recurrence-free survival. Analyses } \\
\text { are adjusted for gender, age at diagnosis, tumour stage and treatment. To facilitate } \\
\text { comparisons between } A P C \text { wild-type/mutated tumour groups, hazard ratios are presented } \\
\text { for all pairwise combinations of reference states. }\end{array}$} \\
\hline
\end{tabular}

sites or when comparing tumours with one or two detected hits. While the number of intact $\beta$-catenin binding sites appears to be important for tumour initiation, with different 'just-right' mutation spectra in the embryologically distinct proximal and distal colon (Albuquerque et al, 2010; Christie et al, 2013), APC mutation genotypes appear to have less influence on disease progression.

Although further large cohort studies will be required to validate our findings, our data suggest a potential role for joint MSI and $A P C$ testing in risk stratification for patients with CRC. In particular, more aggressive investigation and therapy may be indicated for patients with poor prognosis $A P C$-wt/MSS proximal

\section{Table 3B. (B) Validation cohort}

\begin{tabular}{|c|c|c|c|c|}
\hline & \multicolumn{2}{|c|}{ Overall survival } & \multicolumn{2}{|c|}{ Recurrence-free surviva } \\
\hline & $\mathrm{HR}(95 \% \mathrm{Cl})$ & $P$ & $\mathrm{HR}(95 \% \mathrm{Cl})$ & $P$ \\
\hline $\begin{array}{l}\text { MSI vs APC-mt/ } \\
\text { MSS }\end{array}$ & $1.21(0.63-2.34)$ & 0.569 & $0.70(0.32-1.54)$ & 0.375 \\
\hline $\begin{array}{l}\text { APC-wt/MSS/ } \\
\text { vs MSI }\end{array}$ & $2.50(1.25-4.98)$ & $0.010^{*}$ & $3.06(1.34-6.98)$ & $0.008^{*}$ \\
\hline $\begin{array}{l}\text { APC-wt/MSS vs } \\
\text { APC-mt/MSS }\end{array}$ & $3.02(1.67-5.47)$ & $<0.001^{*}$ & $2.14(1.10-4.18)$ & $0.025^{\star}$ \\
\hline Age (Decades) & 1.45 (1.15-1.83) & $0.002^{\star}$ & $1.12(0.87-1.44)$ & 0.374 \\
\hline $\begin{array}{l}\text { Gender (Female } \\
\text { vs Male) }\end{array}$ & $0.37(0.22-0.63)$ & $<0.001^{*}$ & $0.47(0.26-0.85)$ & $0.012^{\star}$ \\
\hline Stage II vs I & $0.74(0.22-2.51)$ & 0.630 & $2.23(0.30-16.77)$ & 0.437 \\
\hline Stage III vs I & $1.17(0.34-4.06)$ & 0.809 & $4.21(0.55-32.46)$ & 0.167 \\
\hline Stage IV vs I & $4.86(1.22-19.34)$ & $0.025^{\star}$ & & \\
\hline $\begin{array}{l}\text { Chemotherapy } \\
\text { (Yes vs No) }\end{array}$ & $1.26(0.68-2.32)$ & 0.458 & $0.89(0.43-1.82)$ & 0.742 \\
\hline Events/N & $65 / 201$ & & $49 / 185$ & \\
\hline
\end{tabular}

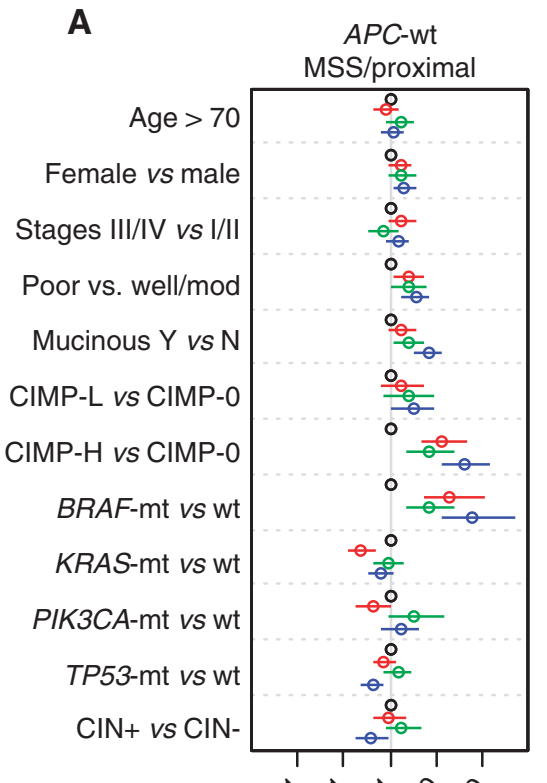

$0.0,0.0,0$

Odds ratio
B

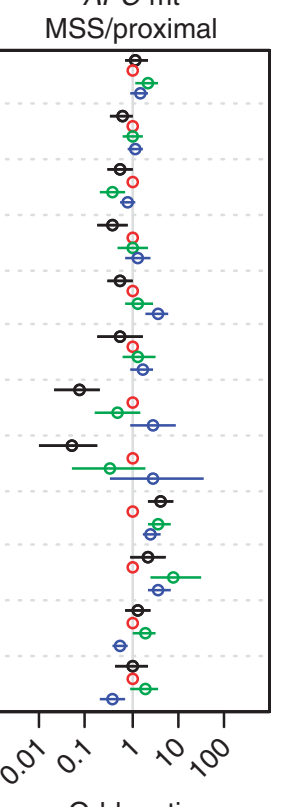

C

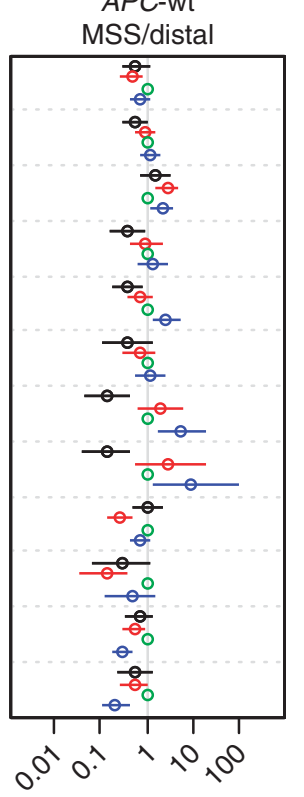

Odds ratio
D

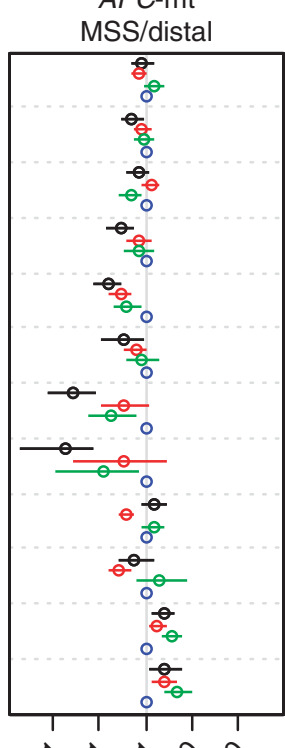

$0.0 .0,0$

Odds ratio
E MSI/proximal

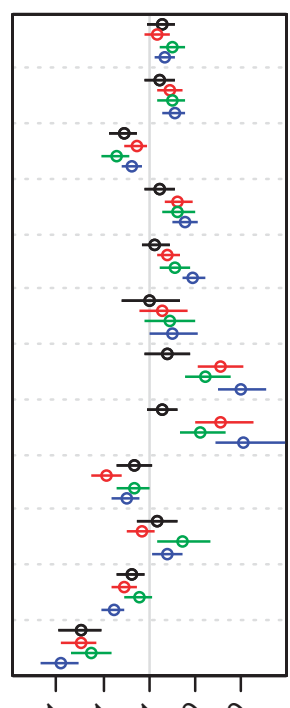

0.0

$A P C$-wt/MSS/proximal

APC-mt/MSS/proximal

Odds ratio

Figure 3. Comparison of clinicopathological and molecular characteristics between colorectal cancer groups defined by APC mutation status, microsatellite instability and tumour location. Odds ratios (circles) and 95\% confidence intervals (lines) for (A) APC-wt/MSS proximal cancers, (B) APC-mt/MSS proximal cancers, (C) APC-wt/MSS distal cancers, (D) APC-mt/MSS distal cancers, relative to each other. (E) Comparison of MSI proximal cancers to the four MSS tumour groups. Abbreviations: CIN chromosomal instability; CIMP, CpG island methylator phenotype; MSS/MSI, microsatellite stable/unstable. 
Table 4. Likelihood ratio tests evaluating the fit of OS and RFS data for patients with microsatellite stable, proximal colon cancer when adding APC mutation status to Cox proportional-hazard models with CIMP-H, BRAF, KRAS, PIK3CA, TP53 or CIN status (labeled X) or vice versa

\begin{tabular}{l|l|c|c|c|c|c|c|c|}
\cline { 2 - 8 } & \multicolumn{9}{|c|}{ Overall survival } & \multicolumn{4}{c|}{ Recurrence-free survival } \\
\cline { 2 - 9 } & Events/N & P (add APC) & P (add X) & AIC (APC)-AIC (X) & Events/N & P (add APC) & P (add X) & AIC (APC)-AIC (X) \\
\hline CIMP status & $58 / 149$ & $0.003^{*}$ & 0.542 & -9.3 & $43 / 123$ & $0.021^{*}$ & 0.731 & -6.7 \\
\hline BRAF-mt & $79 / 220$ & $0.036^{*}$ & 0.323 & -3.4 & $46 / 130$ & $0.014^{*}$ & 0.464 & -5.6 \\
\hline KRAS-mt & $79 / 220$ & $0.012^{*}$ & 0.827 & -6.3 & $46 / 130$ & $0.002^{*}$ & 0.470 & -9.4 \\
\hline PIK3CA-mt & $79 / 220$ & $0.010^{*}$ & 0.181 & -4.8 & $46 / 130$ & $0.002^{*}$ & 0.487 & -8.8 \\
\hline TP53-mt & $79 / 220$ & $0.007^{*}$ & 0.403 & -6.7 & $46 / 130$ & $0.001^{*}$ & 0.178 & -8.4 \\
\hline CIN status & $71 / 194$ & $<0.001^{*}$ & 0.904 & -11.2 & $44 / 123$ & $0.001^{*}$ & 0.096 & -8.1 \\
\hline $\begin{array}{l}\text { Abbreviations: CIMP = CpG island methylator phenotype; CIN = chromosomal instability; MSS = microsatellite stable; OS = overall survival; RFS = recurrence-free survival. *P<0.05. Differences } \\
\text { in Aikake Information Criteria (AIC) are shown for the comparison of models with APC mutation against the relevant molecular feature of interest; negative values of the AIC difference indicate a } \\
\text { better fit for the APC mutation models. }\end{array}$ \\
\hline
\end{tabular}

tumours. As $A P C$ is a large gene with mutations occurring throughout the 5' two-thirds of the coding sequence, demonstration of $A P C$-wt status will require substantial sequencing, which would previously have been impractical for clinical purposes. However, with the increasing adoption of massively parallel sequencing in clinical molecular pathology departments, routine $A P C$ sequencing for prognostic purposes will become feasible.

\section{ACKNOWLEDGEMENTS}

We thank all individuals who participated in this study and colleagues who undertook sample and clinical data collection. We acknowledge the Victorian Cancer Biobank for the provision of specimens and BioGrid Australia for providing clinical data. This work was supported by a Cancer Australia Project Grant (APP1030098), a Cancer Council Victoria Grant-in-Aid (APP1060964), Ludwig Institute for Cancer Research, a Cancer Council Victoria Postgraduate Cancer Research Scholarship to MC and a National Health and Medical Research Council of Australia (NHMRC) R.D. Wright Biomedical Career Development Fellowship to OMS (APP1062226). This study was supported in part by the Victorian Government's Operational Infrastructure Support Program.

\section{CONFLICT OF INTEREST}

The authors declare no conflict of interest.

\section{REFERENCES}

Albuquerque C, Baltazar C, Filipe B, Penha F, Pereira T, Smits R, Cravo M, Lage P, Fidalgo P, Claro I, Rodrigues P, Veiga I, Ramos JS, Fonseca I, Leitao CN, Fodde R (2010) Colorectal cancers show distinct mutation spectra in members of the canonical WNT signaling pathway according to their anatomical location and type of genetic instability. Genes Chromosomes Cancer 49: 746-759.

Albuquerque C, Breukel C, van der Luijt R, Fidalgo P, Lage P, Slors FJ, Leitao CN, Fodde R, Smits R (2002) The 'just-right' signaling model: APC somatic mutations are selected based on a specific level of activation of the $\beta$-catenin signaling cascade. Hum Mol Genet 11: 1549-1560.

Arnold CN, Goel A, Niedzwiecki D, Dowell JM, Wasserman L, Compton C, Mayer RJ, Bertagnolli MM, Boland CR (2004) APC promoter hypermethylation contributes to the loss of APC expression in colorectal cancers with allelic loss on 5q. Cancer Biol Ther 3: 960-964.

Bettington M, Walker N, Clouston A, Brown I, Leggett B, Whitehall V (2013) The serrated pathway to colorectal carcinoma: current concepts and challenges. Histopathology 62: 367-386.

Bettington M, Walker N, Rosty C, Brown I, Clouston A, Wockner L, Whitehall V, Leggett B (2014) Critical appraisal of the diagnosis of the sessile serrated adenoma. Am J Surg Pathol 38: 158-166.
Birnbaum DJ, Laibe S, Ferrari A, Lagarde A, Fabre AJ, Monges G, Birnbaum D, Olschwang S (2012) Expression profiles in stage II colon cancer according to APC gene status. Transl Oncol 5: 72-76.

Boland CR, Thibodeau SN, Hamilton SR, Sidransky D, Eshleman JR, Burt RW, Meltzer SJ, Rodriguez-Bigas MA, Fodde R, Ranzani GN, Srivastava S (1998) A National Cancer Institute Workshop on Microsatellite Instability for cancer detection and familial predisposition: development of international criteria for the determination of microsatellite instability in colorectal cancer. Cancer Res 58: 5248-5257.

Chang CC, Lin CJ (2001) Training nu-support vector classifiers: theory and algorithms. Neural Comput 13: 2119-2147.

Chen SP, Wu CC, Lin SZ, Kang JC, Su CC, Chen YL, Lin PC, Chiu SC, Pang CY, Harn HJ (2009) Prognostic significance of interaction between somatic APC mutations and 5-fluorouracil adjuvant chemotherapy in Taiwanese colorectal cancer subjects. Am J Clin Oncol 32: 122-126.

Christie M, Jorissen RN, Mouradov D, Sakthianandeswaren A, Li S, Day F, Tsui C, Lipton L, Desai J, Jones IT, McLaughlin S, Ward RL, Hawkins NJ, Ruszkiewicz AR, Moore J, Burgess AW, Busam D, Zhao Q, Strausberg RL, Simpson AJ, Tomlinson IP, Gibbs P, Sieber OM (2013) Different APC genotypes in proximal and distal sporadic colorectal cancers suggest distinct $\mathrm{WNT} / \beta$-catenin signalling thresholds for tumourigenesis. Oncogene 32: 4675-4682.

Conlin A, Smith G, Carey FA, Wolf CR, Steele RJC (2005) The prognostic significance of K-ras, p53, and APC mutations in colorectal carcinoma. Gut 54: 1283-1286.

Day FL, Jorissen RN, Lipton L, Mouradov D, Sakthianandeswaren A, Christie M, Li S, Tsui C, Tie J, Desai J, Xu ZZ, Molloy P, Whitehall V, Leggett BA, Jones IT, McLaughlin S, Ward RL, Hawkins NJ, Ruszkiewicz AR, Moore J, Busam D, Zhao Q, Strausberg RL, Gibbs P, Sieber OM (2013) PIK3CA and $P T E N$ gene and exon mutation-specific clinicopathologic and molecular associations in colorectal cancer. Clin Cancer Res 19: 3285-3296.

de Lau W, Peng WC, Gros P, Clevers H (2014) The R-spondin/Lgr5/Rnf43 module: regulator of Wnt signal strength. Genes Dev 28: 305-316.

De Sousa EMF, Wang X, Jansen M, Fessler E, Trinh A, de Rooij LP, de Jong JH, de Boer OJ, van Leersum R, Bijlsma MF, Rodermond H, van der Heijden M, van Noesel CJ, Tuynman JB, Dekker E, Markowetz F, Medema JP, Vermeulen L (2013) Poor-prognosis colon cancer is defined by a molecularly distinct subtype and develops from serrated precursor lesions. Nat Med 19: 614-618.

Dix BR, Robbins P, Soong R, Jenner D, House AK, Iacopetta BJ (1994) The common molecular genetic alterations in Dukes' B and C colorectal carcinomas are not short-term prognostic indicators of survival. Int $J$ Cancer 59: 747-751.

Fearon ER, Vogelstein B (1990) A genetic model for colorectal tumorigenesis. Cell 61: 759-767.

French AJ, Sargent DJ, Burgart LJ, Foster NR, Kabat BF, Goldberg R, Shepherd L, Windschitl HE, Thibodeau SN (2008) Prognostic significance of defective mismatch repair and BRAF V600E in patients with colon cancer. Clin Cancer Res 14: 3408-3415.

Giannakis M, Hodis E, Jasmine Mu X, Yamauchi M, Rosenbluh J, Cibulskis K, Saksena G, Lawrence MS, Qian ZR, Nishihara R, Van Allen EM, Hahn WC, Gabriel SB, Lander ES, Getz G, Ogino S, Fuchs CS, Garraway LA (2014) RNF43 is frequently mutated in colorectal and endometrial cancers. Nat Genet 46(12): 1264-1266. 
Guastadisegni C, Colafranceschi M, Ottini L, Dogliotti E (2010) Microsatellite instability as a marker of prognosis and response to therapy: a metaanalysis of colorectal cancer survival data. Eur J Cancer 46: 2788-2798.

Hsieh JS, Lin SR, Chang MY, Chen FM, Lu CY, Huang TJ, Huang YS, Huang CJ, Wang JY (2005) APC, K-ras, and p53 gene mutations in colorectal cancer patients: correlation to clinicopathologic features and postoperative surveillance. Am Surg 71: 336-343.

Irizarry RA, Hobbs B, Collin F, Beazer-Barclay YD, Antonellis KJ, Scherf U, Speed TP (2003) Exploration, normalization, and summaries of high density oligonucleotide array probe level data. Biostatistics 4: 249-264.

Jho EH, Zhang T, Domon C, Joo CK, Freund JN, Costantini F (2002) Wnt/ßcatenin/Tcf signaling induces the transcription of Axin2, a negative regulator of the signaling pathway. Mol Cell Biol 22: 1172-1183.

Johnson WE, Li C, Rabinovic A (2007) Adjusting batch effects in microarray expression data using empirical Bayes methods. Biostatistics 8: 118-127.

Leggett B, Whitehall V (2010) Role of the serrated pathway in colorectal cancer pathogenesis. Gastroenterology 138: 2088-2100.

Liu W, Dong X, Mai M, Seelan RS, Taniguchi K, Krishnadath KK, Halling KC, Cunningham JM, Boardman LA, Qian C, Christensen E, Schmidt SS, Roche PC, Smith DI, Thibodeau SN (2000) Mutations in AXIN2 cause colorectal cancer with defective mismatch repair by activating $\beta$-catenin/ TCF signalling. Nat Genet 26: 146-147.

Lochhead P, Kuchiba A, Imamura Y, Liao X, Yamauchi M, Nishihara R, Qian ZR, Morikawa T, Shen J, Meyerhardt JA, Fuchs CS, Ogino S (2013) Microsatellite instability and BRAF mutation testing in colorectal cancer prognostication. J Natl Cancer Inst 105: 1151-1156.

Løvig T, Meling GI, Diep CB, Thorstensen L, Norheim Andersen S, Lothe RA, Rognum TO (2002) APC and CTNNB1 mutations in a large series of sporadic colorectal carcinomas stratified by the microsatellite instability status. Scand J Gastroenterol 37: 1184-1193.

Marisa L, de Reynies A, Duval A, Selves J, Gaub MP, Vescovo L, Etienne-Grimaldi MC, Schiappa R, Guenot D, Ayadi M, Kirzin S, Chazal M, Flejou JF, Benchimol D, Berger A, Lagarde A, Pencreach E, Piard F, Elias D, Parc Y, Olschwang S, Milano G, Laurent-Puig P, Boige V (2013) Gene expression classification of colon cancer into molecular subtypes: characterization, validation, and prognostic value. PLoS Med 10: e1001453.

Meguid RA, Slidell MB, Wolfgang CL, Chang DC, Ahuja N (2008) Is there a difference in survival between right- versus left-sided colon cancers? Ann Surg Oncol 15: 2388-2394.

Miyoshi Y, Nagase H, Ando H, Horii A, Ichii S, Nakatsuru S, Aoki T, Miki Y, Mori T, Nakamura Y (1992) Somatic mutations of the APC gene in colorectal tumors: mutation cluster region in the APC gene. Hum Mol Genet 1: 229-233.

Mouradov D, Domingo E, Gibbs P, Jorissen RN, Li S, Soo PY, Lipton L, Desai J, Danielsen HE, Oukrif D, Novelli M, Yau C, Holmes CC, Jones IT, McLaughlin S, Molloy P, Hawkins NJ, Ward R, Midgely R, Kerr D, Tomlinson IP, Sieber OM (2013) Survival in stage II/III colorectal cancer is independently predicted by chromosomal and microsatellite instability, but not by specific driver mutations. Am J Gastroenterol 108: 1785-1793.

Munro AJ, Lain S, Lane DP (2005) P53 abnormalities and outcomes in colorectal cancer: a systematic review. Br J Cancer 92: 434-444.

Muto Y, Maeda T, Suzuki K, Kato T, Watanabe F, Kamiyama H, Saito M, Koizumi K, Miyaki Y, Konishi F, Alonso S, Perucho M, Rikiyama T (2014) DNA methylation alterations of AXIN2 in serrated adenomas and colon carcinomas with microsatellite instability. BMC Cancer 14: 466.

Network TCGA (2012) Comprehensive molecular characterization of human colon and rectal cancer. Nature 487: 330-337.

Ng K, Schrag D (2010) Microsatellite instability and adjuvant fluorouracil chemotherapy: a mismatch? J Clin Oncol 28: 3207-3210.

Ogino S, Shima K, Meyerhardt JA, McCleary NJ, Ng K, Hollis D, Saltz LB, Mayer RJ, Schaefer P, Whittom R, Hantel A, Benson 3rd AB, Spiegelman D, Goldberg RM, Bertagnolli MM, Fuchs CS (2012) Predictive and prognostic roles of $B R A F$ mutation in stage III colon cancer: results from intergroup trial CALGB 89803. Clin Cancer Res 18: 890-900.

Pai RK, Jayachandran P, Koong AC, Chang DT, Kwok S, Ma L, Arber DA, Balise RR, Tubbs RR, Shadrach B (2012) BRAF-mutated, microsatellitestable adenocarcinoma of the proximal colon: an aggressive adenocarcinoma with poor survival, mucinous differentiation, and adverse morphologic features. Am J Surg Pathol 36: 744-752.
Phipps AI, Limburg PJ, Baron JA, Burnett-Hartman AN, Weisenberger DJ, Laird PW, Sinicrope FA, Rosty C, Buchanan DD, Potter JD, Newcomb PA (2015) Association between molecular subtypes of colorectal cancer and patient survival. Gastroenterology 148: 77-87e72.

Popat S, Hubner R, Houlston RS (2005) Systematic review of microsatellite instability and colorectal cancer prognosis. J Clin Oncol 23: 609-618.

Popovici V, Budinska E, Tejpar S, Weinrich S, Estrella H, Hodgson G, Van Cutsem E, Xie T, Bosman FT, Roth AD, Delorenzi M (2012) Identification of a poor-prognosis $B R A F$-mutant-like population of patients with colon cancer. J Clin Oncol 30: 1288-1295.

Prenen H, Tejpar S, Van Cutsem E (2010) New strategies for treatment of KRAS mutant metastatic colorectal cancer. Clin Cancer Res 16: 2921-2926.

Rowan AJ, Lamlum H, Ilyas M, Wheeler J, Straub J, Papadopoulou A, Bicknell D, Bodmer WF, Tomlinson IP (2000) APC mutations in sporadic colorectal tumors: A mutational "hotspot" and interdependence of the "two hits". Proc Natl Acad Sci USA 97: 3352-3357.

Russo A, Bazan V, Iacopetta B, Kerr D, Soussi T, Gebbia N (2005) The TP53 colorectal cancer international collaborative study on the prognostic and predictive significance of $p 53$ mutation: influence of tumor site, type of mutation, and adjuvant treatment. J Clin Oncol 23: 7518-7528.

Samowitz WS, Sweeney C, Herrick J, Albertsen H, Levin TR, Murtaugh MA, Wolff RK, Slattery ML (2005) Poor survival associated with the BRAF V600E mutation in microsatellite-stable colon cancers. Cancer Res 65: 6063-6069.

Segditsas S, Sieber OM, Rowan A, Setien F, Neale K, Phillips RK, Ward R, Esteller M, Tomlinson IP (2008) Promoter hypermethylation leads to decreased APC mRNA expression in familial polyposis and sporadic colorectal tumours, but does not substitute for truncating mutations. Exp Mol Pathol 85: 201-206.

Sinicrope FA, Sargent DJ (2012) Molecular pathways: microsatellite instability in colorectal cancer: prognostic, predictive, and therapeutic implications. Clin Cancer Res 18: 1506-1512.

Sinicrope FA, Shi Q, Smyrk TC, Thibodeau SN, Dienstmann R, Guinney J, Bot BM, Tejpar S, Delorenzi M, Goldberg RM, Mahoney M, Sargent DJ, Alberts SR (2015) Molecular markers identify subtypes of stage III colon cancer associated with patient outcomes. Gastroenterology 148: 88-99.

Smyth GK (2004) Linear models and empirical bayes methods for assessing differential expression in microarray experiments. Stat Appl Genet Mol Biol 3: Article3.

Snover DC (2011) Update on the serrated pathway to colorectal carcinoma. Hum Pathol 42: 1-10.

Stewart BW, Wild C (2014) World Cancer Report 2014International Agency for Research on Cancer: Lyon.

The R Core Development Team (2013) R: A Language and Environment for Statistical Computing. R Foundation for Statistical Computing: Vienna, Austria.

Tie J, Gibbs P, Lipton L, Christie M, Jorissen RN, Burgess AW, Croxford M, Jones I, Langland R, Kosmider S, McKay D, Bollag G, Nolop K, Sieber OM, Desai J (2011) Optimizing targeted therapeutic development: analysis of a colorectal cancer patient population with the BRAF ${ }^{V 600 E}$ mutation. Int J Cancer 128: 2075-2084.

Walther A, Houlston R, Tomlinson I (2008) Association between chromosomal instability and prognosis in colorectal cancer: a metaanalysis. Gut 57: 941-950.

Ward RL, Cheong K, Ku SL, Meagher A, O’Connor T, Hawkins NJ (2003) Adverse prognostic effect of methylation in colorectal cancer is reversed by microsatellite instability. J Clin Oncol 21: 3729-3736.

Wong R (2010) Proximal tumors are associated with greater mortality in colon cancer. J Gen Intern Med 25: 1157-1163.

Yau C, Mouradov D, Jorissen RN, Colella S, Mirza G, Steers G, Harris A, Ragoussis J, Sieber O, Holmes CC (2010) A statistical approach for detecting genomic aberrations in heterogeneous tumor samples from single nucleotide polymorphism genotyping data. Genome Biol 11: R92.

This work is published under the standard license to publish agreement. After 12 months the work will become freely available and the license terms will switch to a Creative Commons AttributionNonCommercial-Share Alike 4.0 Unported License.

\section{Supplementary Information accompanies this paper on British Journal of Cancer website (http://www.nature.com/bjc)}

